\title{
Los primeros retratos de Ignacio y los inicios de la iconografía ignaciana*
}

Ignacio's first portraits and the beginnings of Ignatian iconography

\author{
Carlos A. Page ** $^{*}$
}

DOI: https://doi.org/10.31057/2314.3908.v7.n2.27671

Resumen: A partir de una máscara mortuoria se comenzaron a pintar retratos de San Ignacio en Europa, hasta comenzar a trazar una serie sobre los acontecimientos más importantes de su vida. Presentamos estas noticias para llegar a los modelos de Rubens que fueron los que en definitiva prevalecieron e influyeron en todo el mundo para iniciar una clásica iconografía, cuyos antecedentes y posterior desarrollo contó con destacados artistas, no solo en el ámbito europeo sino también en América.

Palabras clave: iconografía ignaciana; retratística; Peter Paul Rubens; San Ignacio.

\begin{abstract}
From a mortuary mask began to paint portraits of St. Ignatius in Europe, until he began to draw a series about the most important events of his life. We present this news to reach the Rubens models that were the ones that ultimately prevailed and influenced the whole world to start a classic iconography, whose background and subsequent development featured prominent artists, not only in Europe but also in America.
\end{abstract}

Keyword: Ignatian iconography; portraitist; Peter Paul Rubens; San Ignacio.

\footnotetext{
* Conferencia presentada en la inauguración de la exposición "Imaginar lo invisible. Misión y utopía jesuita en el Perú". Lima. Galería Municipal de Arte "Pancho Fierro", 19 de setiembre 2018, en el marco de los 450 años de los jesuitas en Perú, junto al P. Juan Dejó SJ y Elena Amerio.

** CIECS-CONICET/UNC. E-mail: capage1 @ hotmail.com https://orcid.org/0000-0003-4708-5243
} 
Recibido: 4 de julio de 2019.

Evaluado: 18 de setiembre de 2019.

\section{Carlos A. Page}

Arquitecto y Doctor en Historia. Investigador del CONICET, con estudios posdoctorales en el CSIC (España) y en el CNR (Italia). Profesor de posgrado en la UBA y la UNaM. Miembro del Comité Científico del SIEJ (Société Internationale d'Etudes Jésuites) e investigador extranjero del grupo Jesuítas nas Americas (CNPq-Brasil) y el CLEPUL (Centro de Literaturas e Culturas Lusófonas e Europeias da Faculdade de Letras da Lisboa). Dirige el programa "Antiguos Jesuitas en Iberoamérica" (CIECS/CONICET-UNC) y es investigador del Instituto de Teoría e Historia del Arte "Julio E. Payró" (FFyL-UBA). Fundador-Director de la revista científica "IHS. Antiguos jesuitas en Iberoamérica". Publicó alrededor de 300 artículos en revistas científicas y de divulgación en Iberoamérica, Estados Unidos y Europa. Se suman más de 30 libros. Sitio web http://www.carlospage.com.ar/ 
En el mismo día que Ignacio entregó su alma a Dios, el 31 de Julio de 1556, un hermano jesuita le realizó una mascarilla mortuoria de yeso (Fig. 1), coloreada luego por el P. Giovanni Battista Velati, que se conserva en la Curia Generalicia (Roma). Igualmente se tomaron varias copias en cera, aunque el rostro sin vida tenía algunas dificultades (labio superior hinchado, inferior apretado por el yeso, ojos cerrados). Igualmente y en base a la mascarilla, sus compañeros le encargaron un retrato, al artista Jacopino del Conte (Fig. 2). Se le agregó el cerco de la aureola del santo solo después de haber sido canonizado en 1622. Conte fue un pintor italiano que, aunque nació en Florencia, llegó a ser uno de los máximos exponentes del manierismo romano, discípulo de Miguel Ángel.

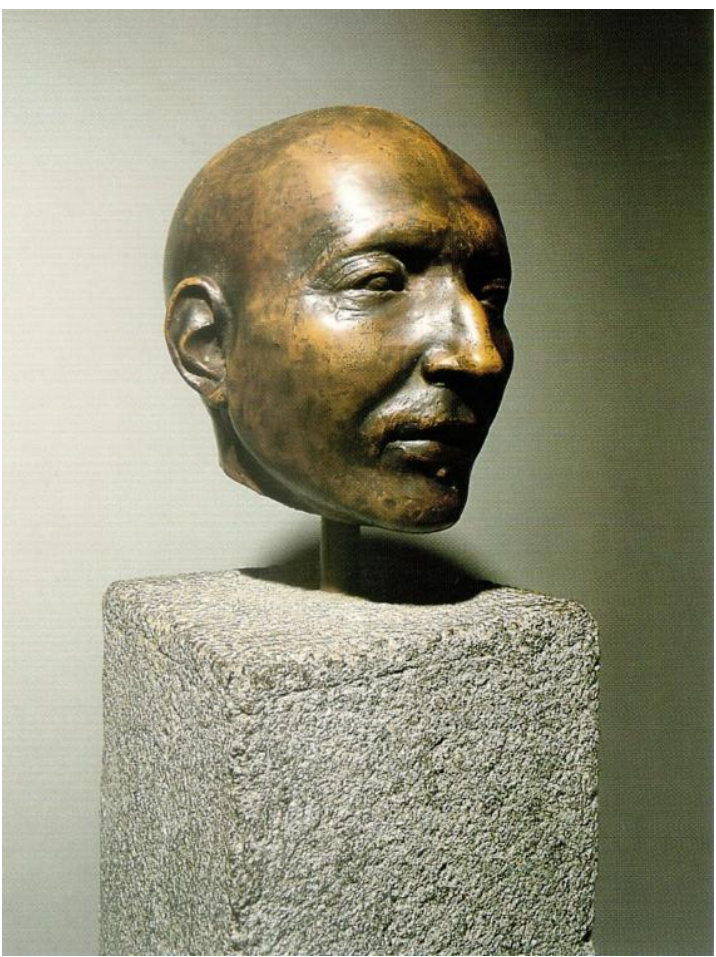

Fig. 1 Busto en bronce de San Ignacio realizada en base a la mascarilla funeraria. Residencia del Gesú, Roma.

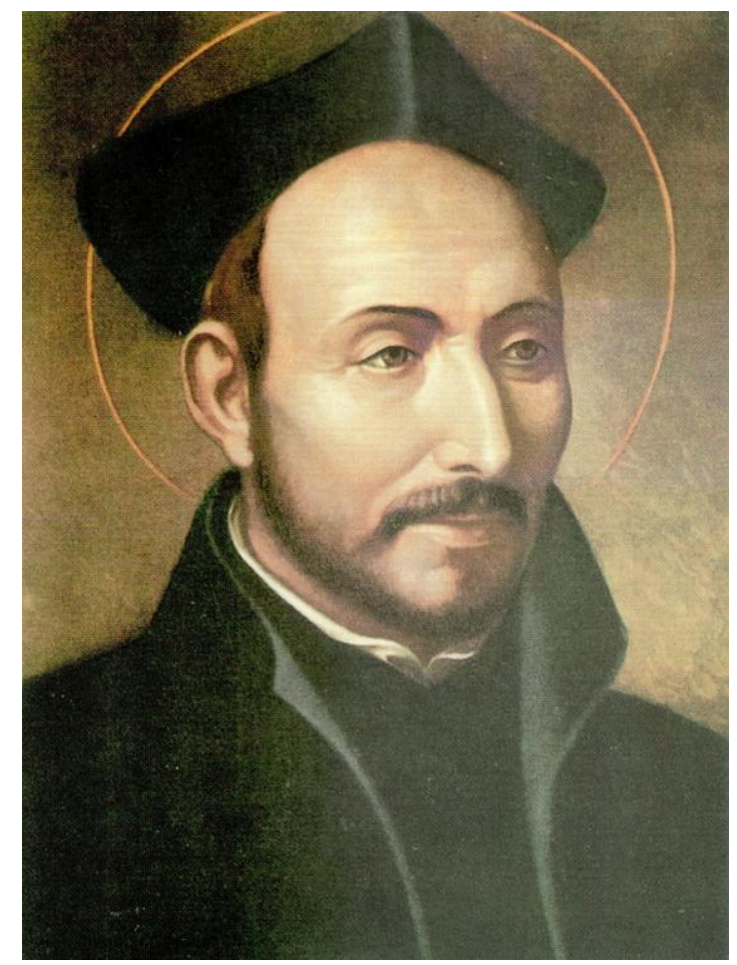

Fig. 2 Retrato de San Ignacio Jacopino del Conte (1556) Casa Generalicia, Roma.
Esta representación de Ignacio fue considerada la mejor, al menos, para los tres primeros generales (Láinez, Borja y Mercuriano), quienes conservaban la imagen viva de quien los había guiado. Pero no es que les haya agradado, sino que la aceptaron, como hicieron con otro retrato que pintó luego el artista español Alonso Sánchez Coello (Fig. 3).

Efectivamente, y por indicación del P. Pedro Ribadeneira, se encargó al famoso pintor valenciano y retratista de la familia real, que lo pintara tomando un modelo en barro, que había hecho el H. Domingo Beltrán, también por comisión del propio Ribadeneira, subsanando los defectos de la mascarilla. Lo hizo en Madrid en 1585, con especial indicación del color del rostro, que le dio también Ribadeneira,

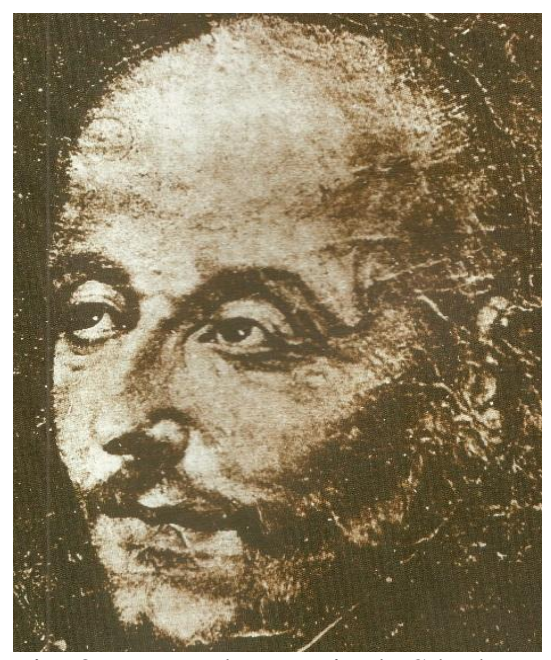

Fig. 3 Retrato de Ignacio de Sánchez Coello (1585), quemado el 11 de mayo de 1931. 
como lo conservaba en su memoria. Luego se hicieron 16 copias, aunque ninguna de la calidad del original. Para algunos había superado a Conte, pero este lienzo, ubicado en la Casa Profesa, lamentablemente se quemó durante la guerra civil española (1931).

A propósito de las mascarillas, diremos que una tercera de yeso, se conserva en la iglesia de Castel Madama, cerca de Tivoli. Se cree que pudo haber sido tomada en vida de Ignacio, como el retrato del Museo de Historia de Arte de Sondrio (Fig. 4), con una posterior inscripción en el marco del P. Nicola Bobadilla (uno de los primeros compañeros de Ignacio). La imagen de perfil fue pintada, según el texto del marco, en 1543, aunque pareciera ser una pintura basada en el grabado del Belga Johan Sadeler de 1580 que se utilizó para la edición veneciana de la vida de Ignacio de Ribadeneira de 1587 (Fig. 5).

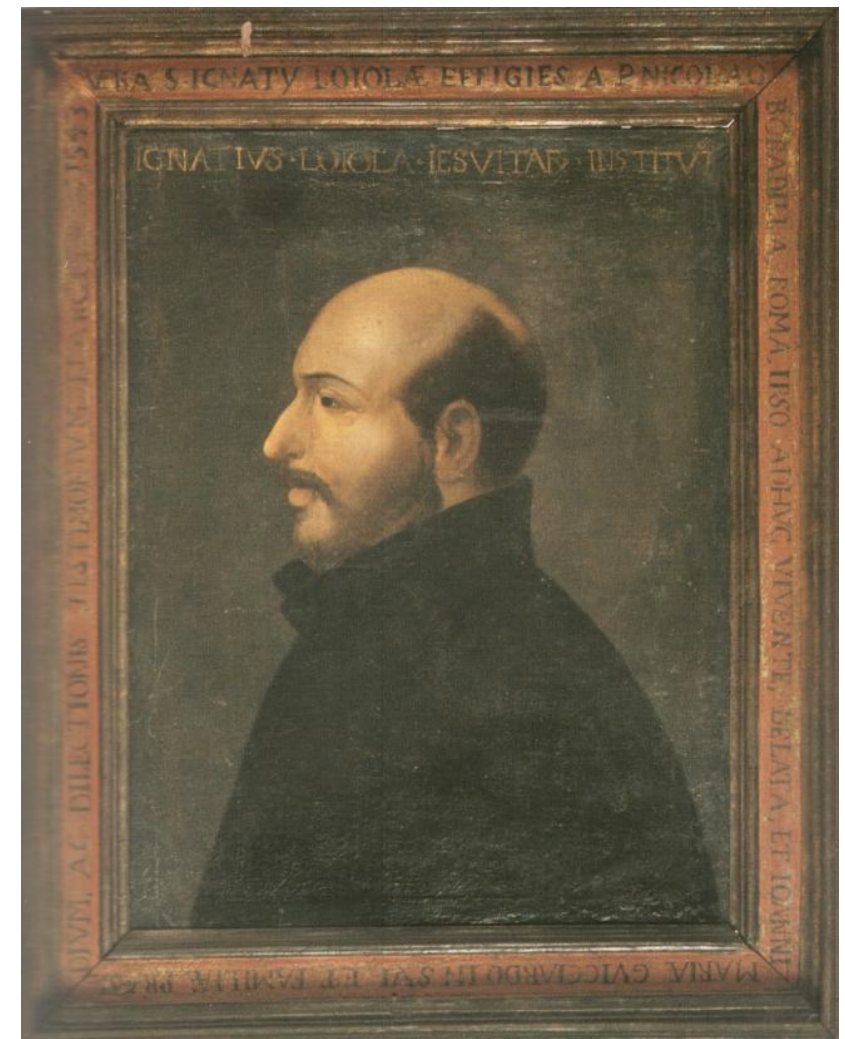

Fig. 4 Retrato de San Ignacio con inscripciones del P. Nicola Bobadilla (1543). Museo Provincial de Sondrio, Roma.

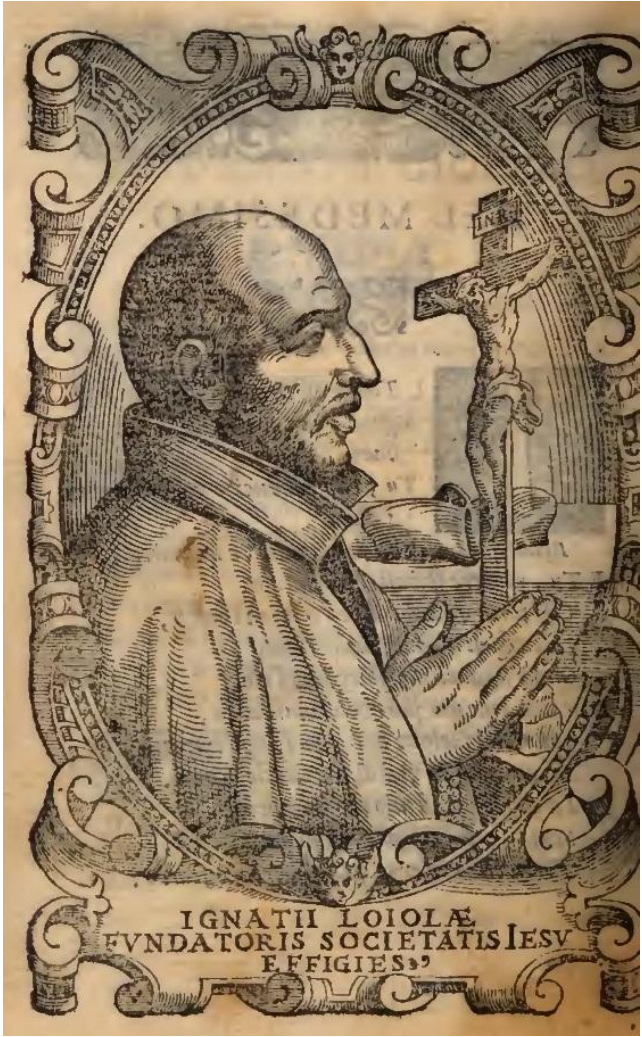

Fig. 5 Retrato de San Ignacio grabado de Johan Sadeler. Vida de Ignacio de Pedro de Rivadeneira. Venecia 1587.

Algunos superiores de la Orden, que habían conocido a Ignacio, a pesar de la aceptación de los generales, no quedaron convencidos del parecido de los retratos pintados. Tal fue el caso del viceprovincial belga P. Olivier Manare (Mannaerts), quien argumentaba que su rostro era demasiado alargado y no reproducía la viveza de sus ojos, ni la espiritualidad que emanaba su persona. Por tanto, encargó en Flandes una nueva pintura en 1598, a un artista que permanece desconocido. Manare intercambió opiniones con el asistente de Alemania y sobre todo con el general Acuaviva, con el objeto de crear un prototipo para seguir en el futuro. La imagen fue enviada de Flandes a Roma, pero Acuaviva, que también tenía la idea del prototipo, ya había preparado otra imagen pequeña que, junto a los jesuitas de Roma, estimaban la más parecida, por lo que la enviaron a grabar.

Llegó la Congregación de Procuradores en Roma de 1600 y los argumentos del P. Manare prevalecieron en el empeño que puso su enviado, el P. Coster, en sostener la

66 Carlos A. Page. Los primeros retratos de Ignacio y los inicios de la iconografía ... 63-75. 
hipótesis que planteaba su superior. No se sabe con precisión de qué obra pequeña estamos hablando, pero lo más probable es que la imagen oval sin bonete, en cobre, que se conserva en la casa provincial de Bruselas (Fig. 6) sea la que prevaleció, aunque el debate continuó encendidamente por un tiempo, hasta que el P. Manare volvió a enviar al P. general otra pintura en bronce. Varios intentos, aunque no todos se han conservado, dificultan la identificación de cada uno de ellos y llega la pregunta: ¿Qué pintor estuvo por ese tiempo en contacto con los jesuitas belgas? Pues, nada menos que Pieter Paul Rubens, aunque éste hizo su definitivo viaje a Roma en 1600, antes del epistolado de los jesuitas belgas y el general, pudo ser autor de uno. Mientras otro pintor puede haber sido el notable flamenco y maestro del anterior, Otto van Veen. Pero Rubens tenía el perfil que buscaban los jesuitas: joven (23 años en 1600), muy talentoso y sobre todo barato. Por eso se cree que el anónimo oval sea de su autoría. De hecho fue el autor de un libro iconográfico pionero, titulado: Vita Beati P. Ignatti Fundatoris Societatis Iesu, que trataremos luego en particular.

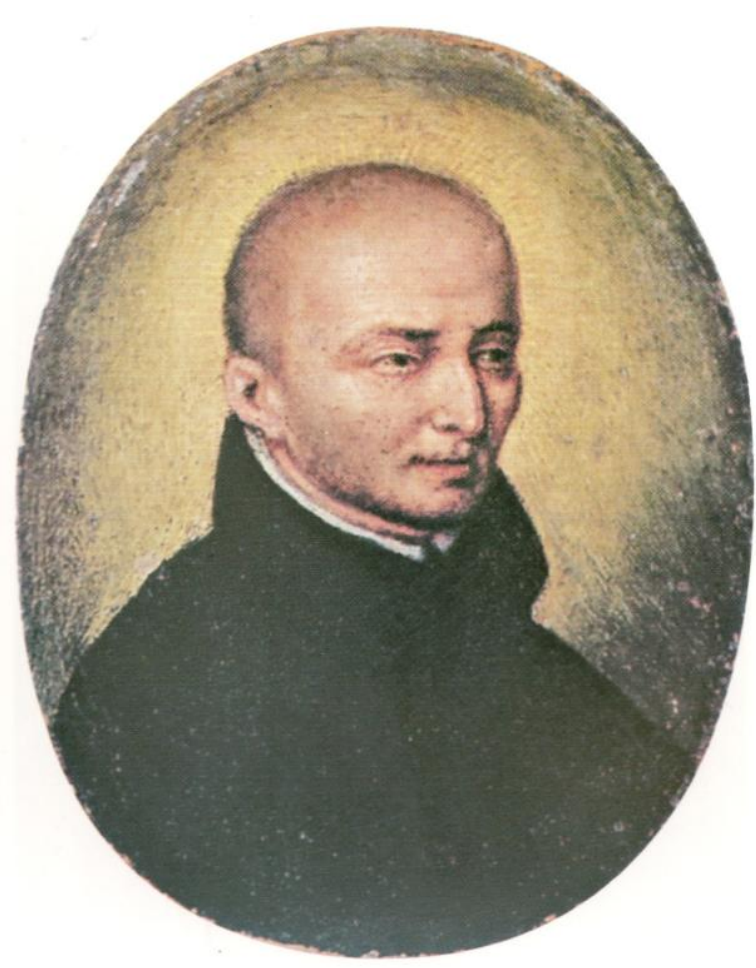

Fig. 6 Retrato de San Ignacio. Anónimo (c. 1600). Casa Provincial de la Compañía de Jesús, Bruselas.

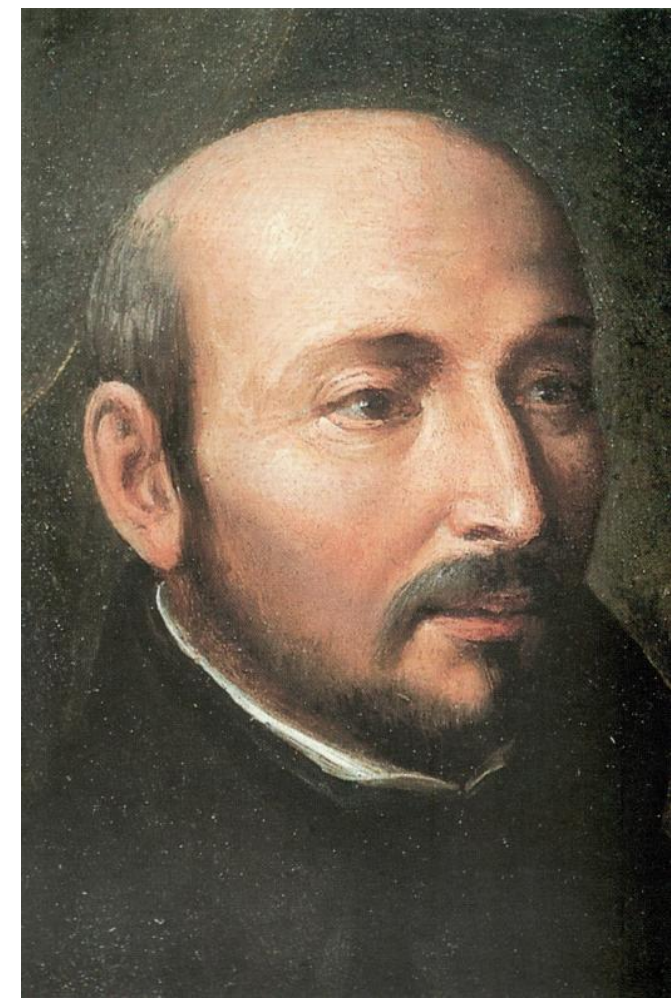

Fig. 7 Retrato de San Ignacio. Anónimo (en bronce). Casa Provincial de la Compañía de Jesús, Bruelas.

Se pintaron otras telas. (Fig. 7) como la conservada en la Casa Provincial de la Compañía de Jesús en Bruselas. Un anónimo cuyo rostro similar al de Conte, se presenta no tan alargado (como quería Manare). También en el Colegio internacional de Gesú, (Fig. 8) se conserva un retrato sosteniendo el libro de los Ejercicios, en cuyo ángulo derecho superior, el resplandor oval de luz con el monograma IHS inscripto, retoma la visión de Ignacio en Manresa de la presencia de Jesús.

Volviendo al libro de Rubens (Fig. 9), diremos que sin ningún lugar a dudas, definió la imagen de Ignacio al ser beatificado a mediados de 1609 y publicado ese año, siendo el P. Manare su propulsor y grabadas probablemente por el famoso artista JeanBaptiste Barbé. Estaba comprobado que las imágenes grabadas podían ser reproducidas 
ilimitadamente a través de la imprenta y comprendida intuitivamente sin que se supiera leer.

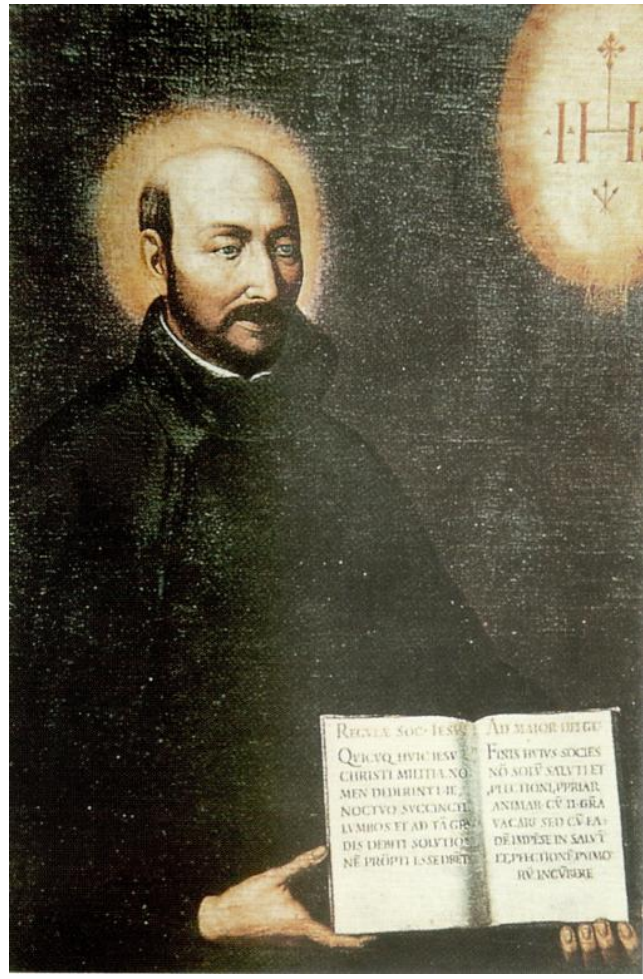

Fig. 8 Retrato de San Ignacio. Anónimo. Colegio Internacional del Gesú. Roma.

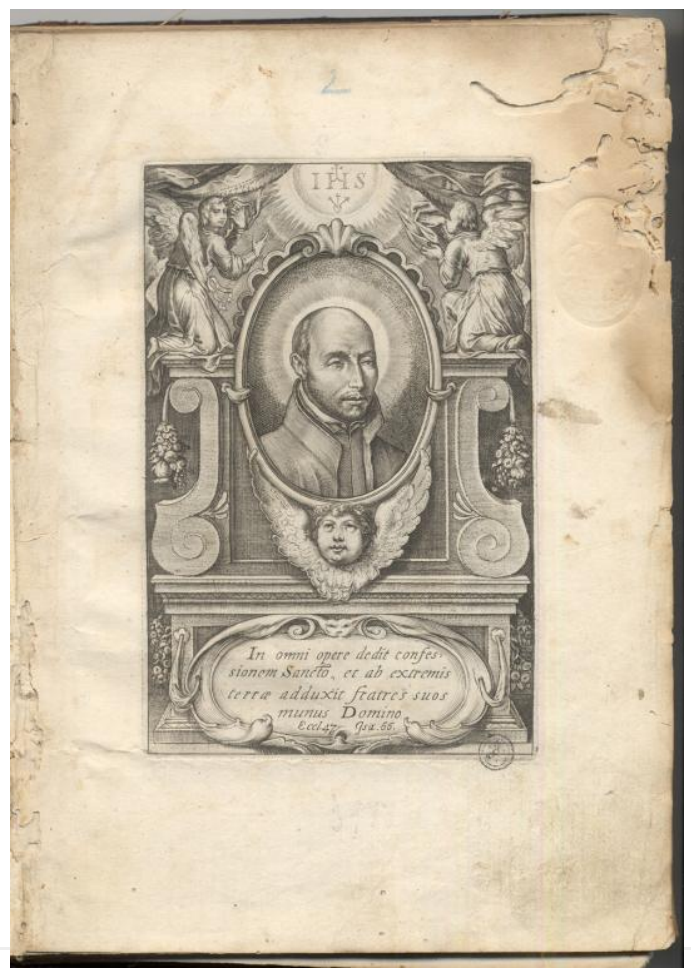

Fig. 10 Retrato de Ignacio. Vita Beati P. Ignatii Loiolae Societatis Iesu Fundatoris (1609). Peter Paul Rubens.

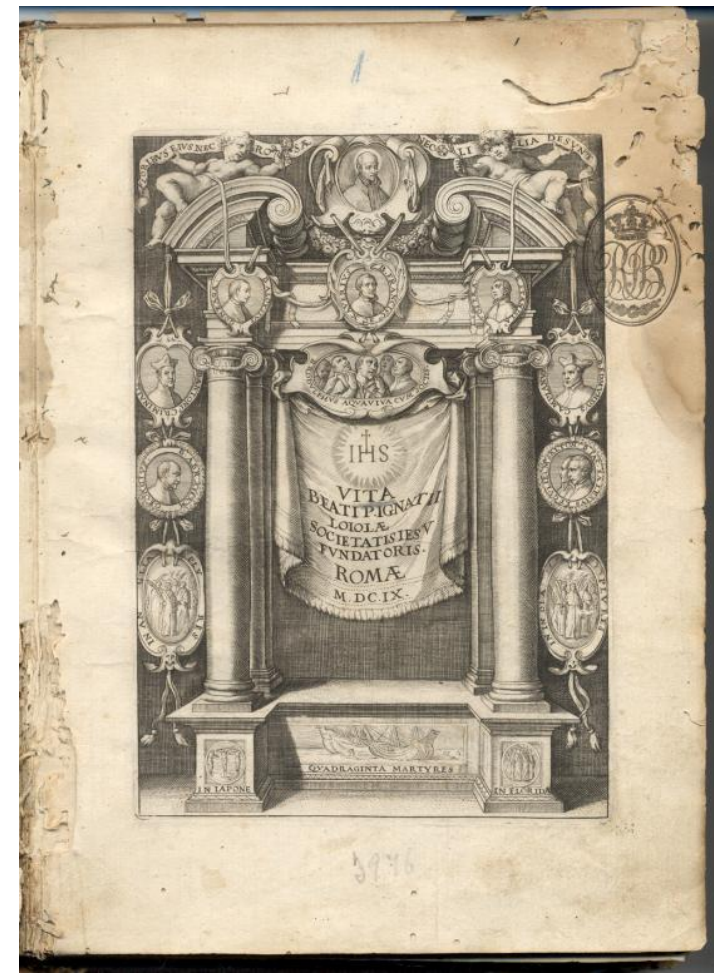

Fig. 9 Vita Beati P. Ignatii Loiolae Societatis Iesu Fundatoris (1609). Peter Paul Rubens.

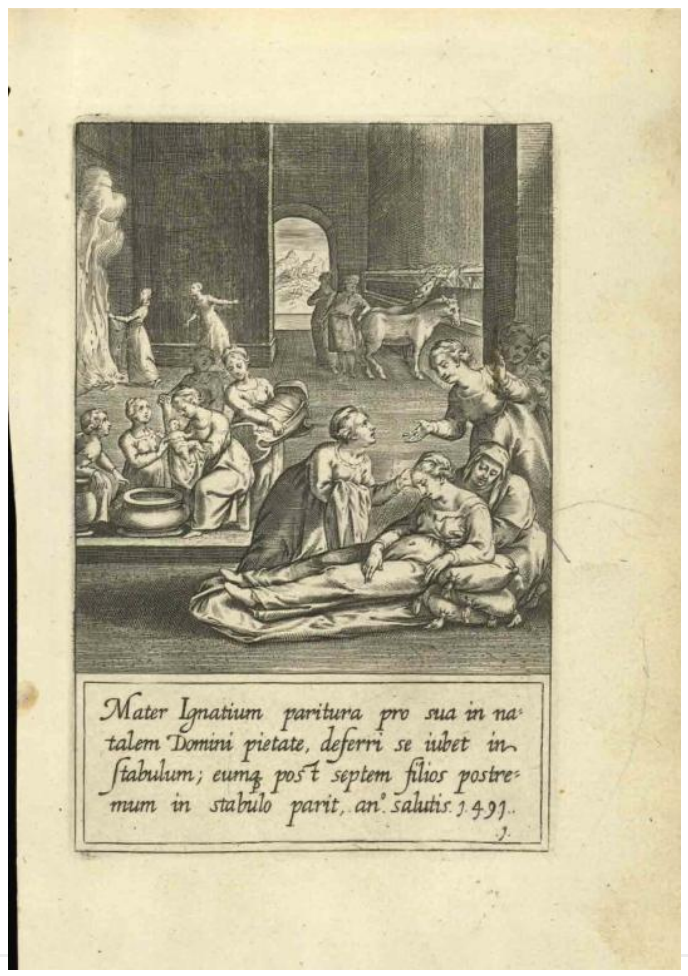

Fig. 11 Nacimiento de Ignacio. Vita Beati P. Ignatii Loiolae Societatis Iesu Fundatoris (1609). Peter Paul Rubens. 


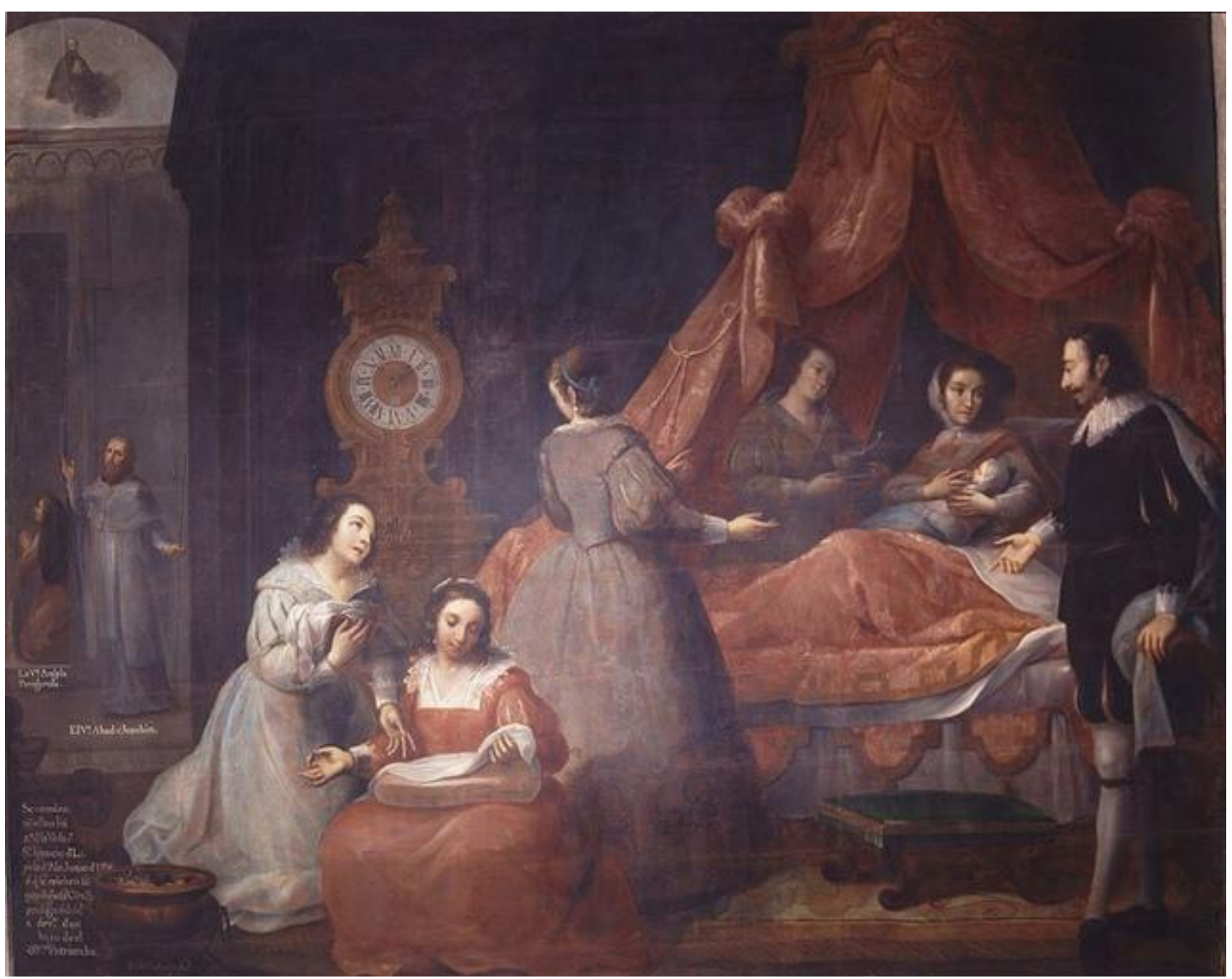

Fig. 12 Nacimiento de San Ignacio. Miguel Cabrera (c.1750). Museo Nacional del Virreinato, Tepozotlán, México

El libro contiene 81 grabados en cobre que representan las escenas más significativas de Ignacio. Imágenes que fueron modélicas en la iconografía ignaciana y que se inician con el retrato de Ignacio (Fig. 10), que sigue la pequeña representación ovalada antes citada. Pero obviamente sus facciones van a ir cambiando, por la edad en que ocurren los acontecimientos. Y reiteramos, los grabados serán la iconografía modélica que tomarán artistas de todo el mundo, como por ejemplo el novohispano Miguel Cabrera que trata, entre otros temas, el nacimiento, tomando el grabado de Rubens (Fig. 11 y 12). También por ejemplo, (Fig. 13) el anónimo que se conserva en el Gesú que representa a San Ignacio recibiendo la aprobación de la Orden por parte del papa Pio III. Incluso en otra vemos (Fig. 14) a San Ignacio escribiendo los Ejercicios Espirituales en la gruta de Manresa, que se encuentra en el claustro de la Universidad Pontificia de Salamanca, como parte de la serie de 28 lienzos que pinta el napolitano Sebastiano Conca. También la muerte de Ignacio (Fig. 15), en la capilla Garnecio, Italia (c. 1600).

En el libro de Rubens, se lo representará en los primeros años con un rostro oblongo, con mejillas ligeramente cóncavas y con una pequeña barba en el mentón. Luego ya aparece con la barba crecida, pero prolijamente rasurada y con el parecido de la portada, como la que se encuentra predicando en una iglesia en Roma (p. 60). De algunos de estos grabados se conservan los dibujos preparatorios, claramente de la mano de Rubens, por ejemplo, el que representa el momento en que Ignacio presenta a Julio III, a los alumnos del Colegio Germánico. 

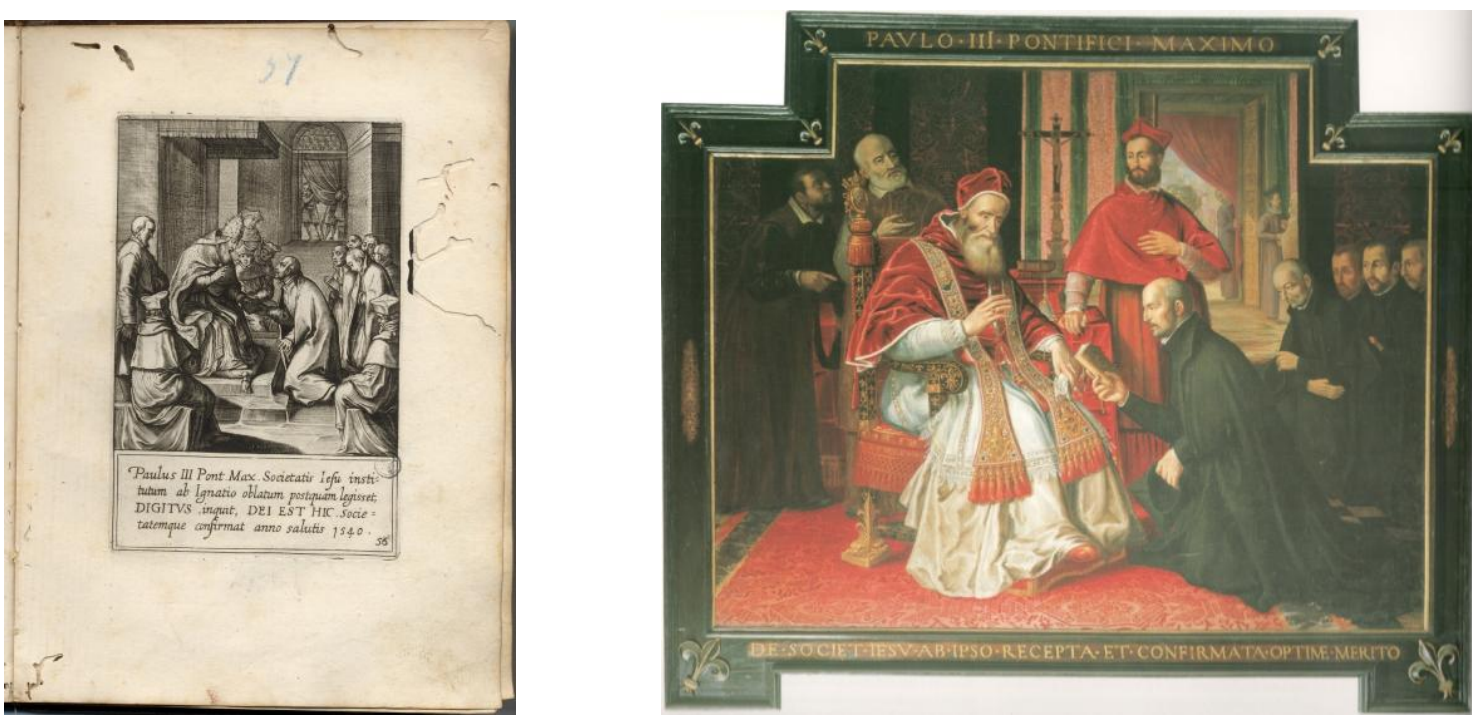

Fig. 13 Paulo III aprobando la Compañía de Jesús. Anónimo. Gesú, Roma.
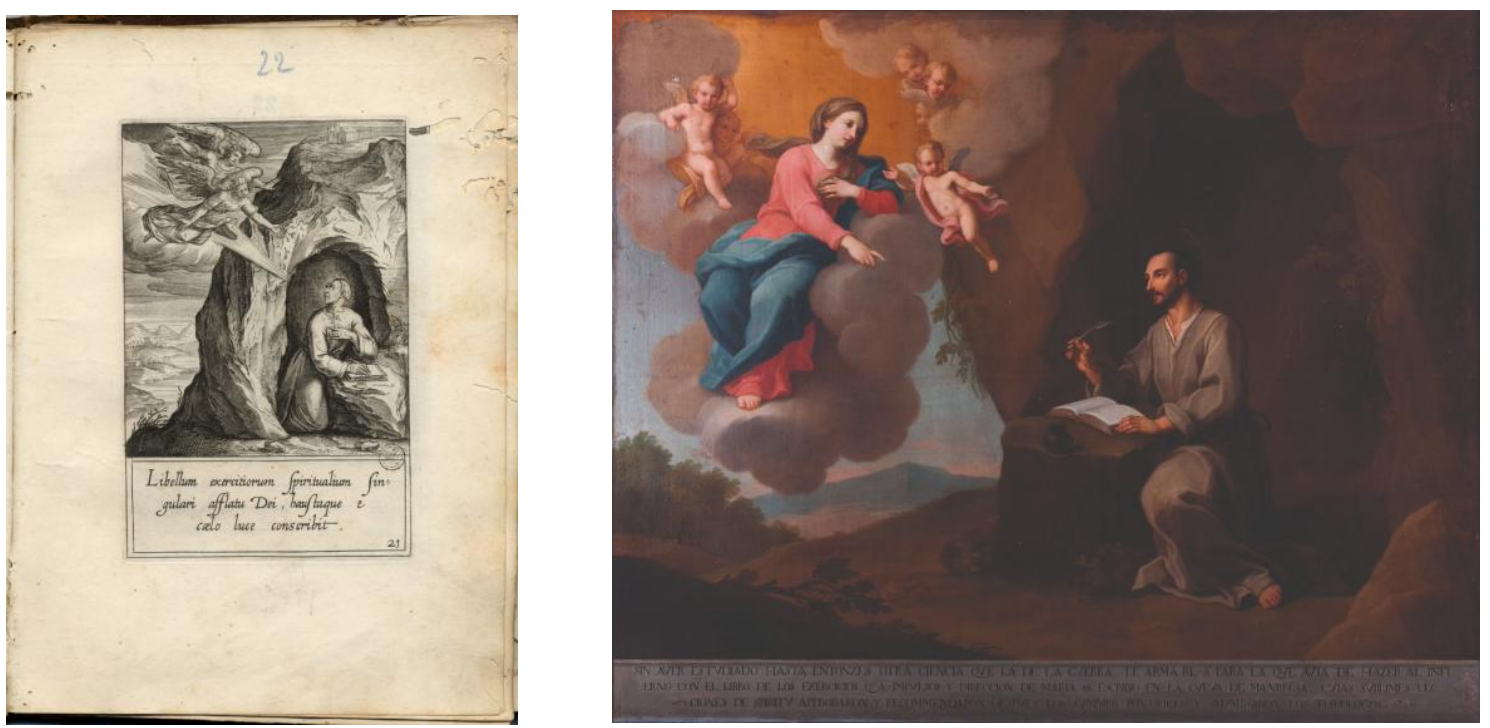

Fig. 14 San Ignacio escribiendo los Ejercicios Espirituales. Sebastiano Conca (c. 1750). Universidad Pontificia de Salamanca.
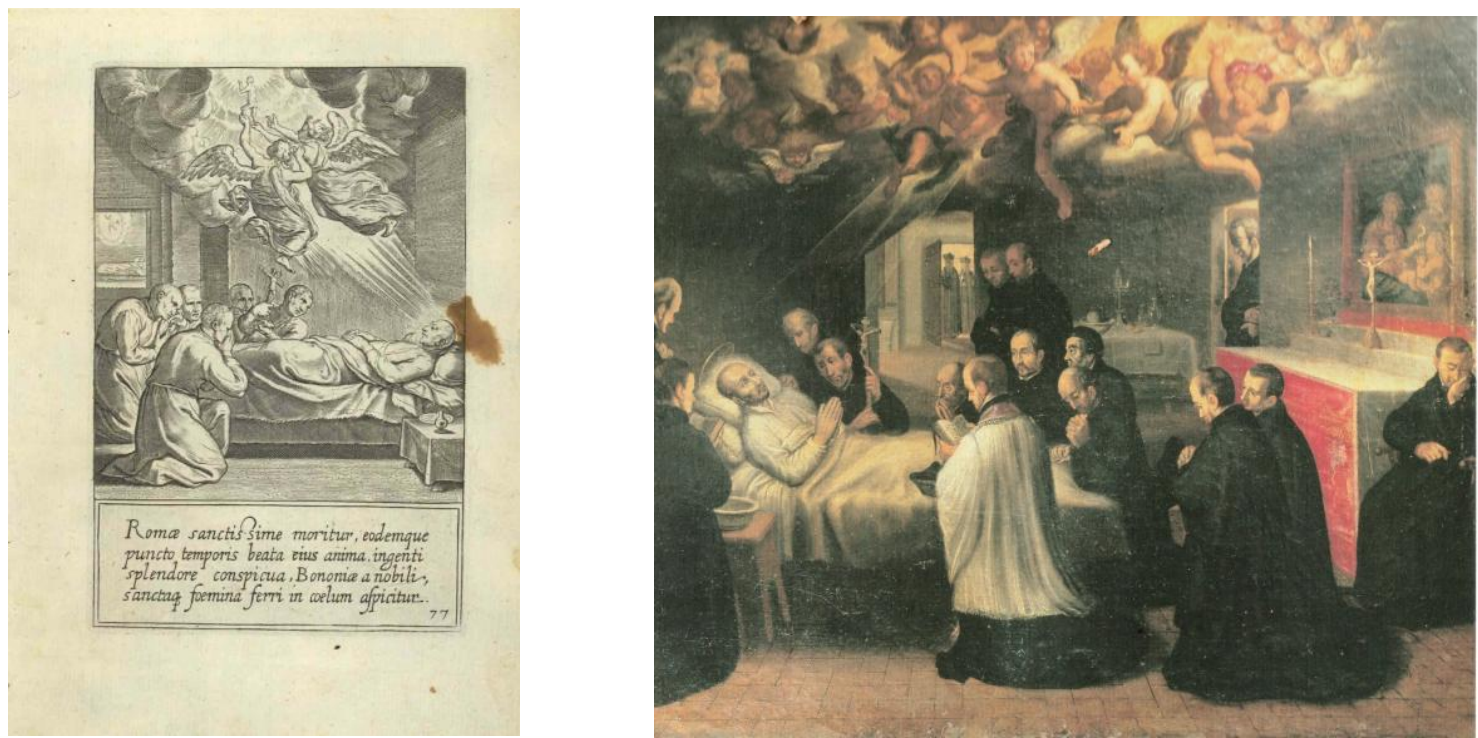

Fig. 15 Muerte de San Ignacio. Anónimo c. 1600 Capilla Garnecio, Italia.

70 Carlos A. Page. Los primeros retratos de Ignacio y los inicios de la iconografía ... 63-75. 
Estos grabados fueron realizados entre 1599 y 1600, cuando Rubens ya estaba en Roma. Pero el papa Clemente VIII, les había prohibido a los jesuitas que evitaran cualquier acción tendiente a preparar la canonización. Por tanto fue toda una "operación secreta", que se sumó por ejemplo a la conocida como "Autobiografía" de Ignacio. Obra que el propio Loyola le trasmitió verbalmente a Luis Gonçalves da Cámara, permaneciendo mucho tiempo inédita, siendo publicada recién en 1904. La "operación" no tan secreta y el sentido marcadamente apologético con vistas a la beatificación y canonización se ocupó sin tapujos el mencionado P. Ribadeneira quien escribió la primera biografía de Ignacio, publicada en latín en 1573 (en castellano 10 años después), con numerosas ediciones posteriores. Incluso Ribadeneira encargó en 1604, luego de la primera de Rubens, una serie compuesta por 15 telas al óleo destinadas a decorar el noviciado de Madrid (hoy en la Casa de Ejercicios de Manresa). También se grabaron en Amberes (Fig. 16), bajo la dirección de los flamencos y hábiles hermanos Cornelio y Teodoro Galle, con la colaboración de otros artistas y editadas por la conocida oficina de Baltasar Moretus en 1610. Año que se produjeron grandes festejos por la beatificación, cuyas solemnidades en Lima, por ejemplo, quedaron registrados en un libro publicado en el taller del italiano Antonio Ricardo, la primera imprenta de América del Sur (Fig. 17).

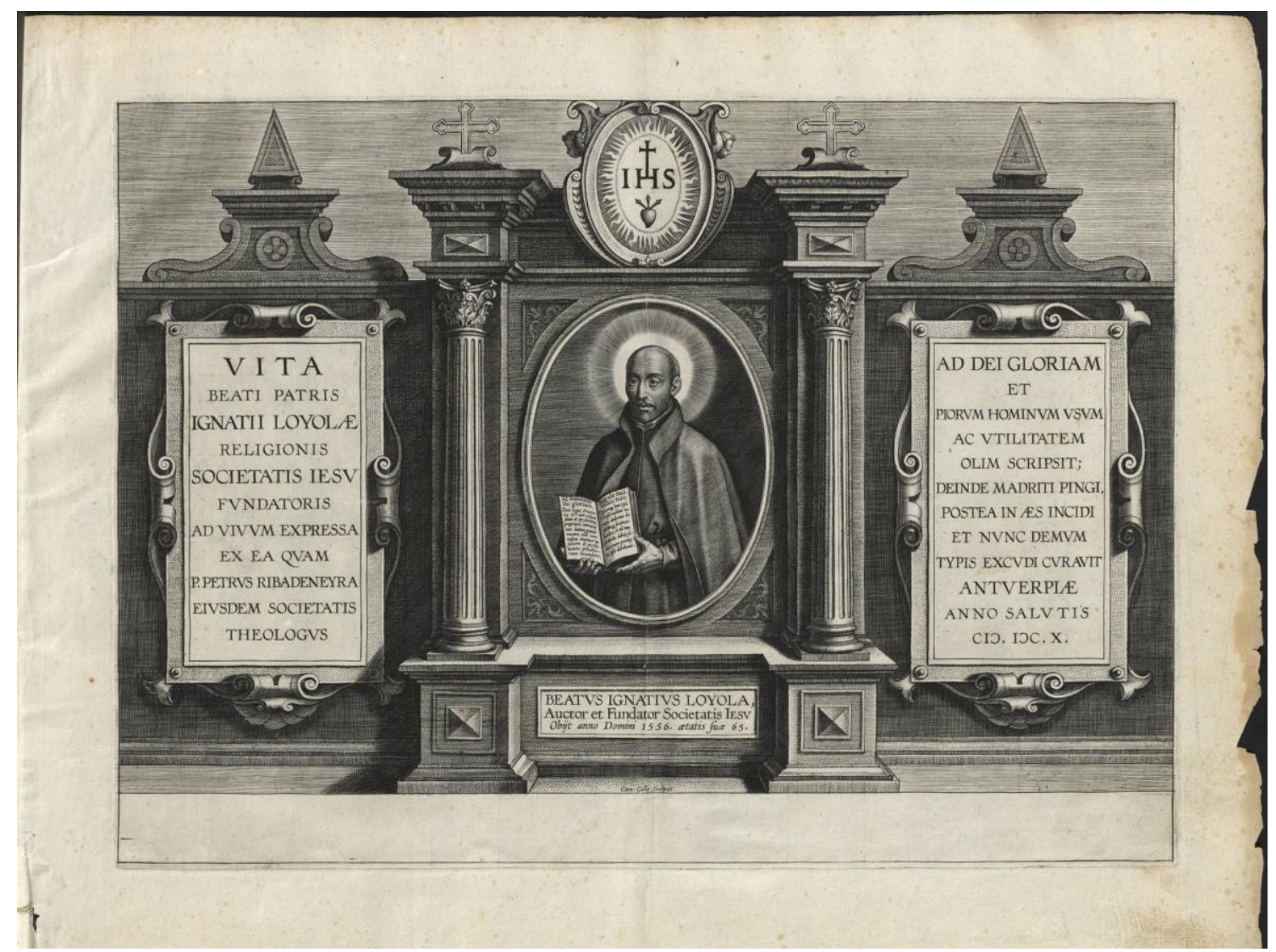

Fig. 16 Cornelio y Teodoro Galle, Vita beati patris Ignatii Loyolae ... Amberes, 1610.

Los Galle tomaron como modelo el ciclo de lienzos que el mismo Ribadeneira había encargado al español Juan de Mesa hacia 1600 (hoy perdidos). Incluso en el transcurso del siglo XVII se imprimieron otras estampas, justamente destinadas a la difusión de la vida del santo. Una de las más interesantes, según algunos autores, es la grabada en 1597 por Pierre Perret, tallador real de Felipe II, en base a otro retrato desconocido y encargada por el mencionado Ribadeneira. Lo interesante de esta obra es que aparece

71 Carlos A. Page. Los primeros retratos de Ignacio y los inicios de la iconografía ... 63-75. 
Ignacio rodeado de cuatro escenas de su vida: su curación milagrosa en Loyola, la aparición de la Virgen, la visión de Cristo en La Storta y la aprobación de la Compañía de Jesús por Paulo III.

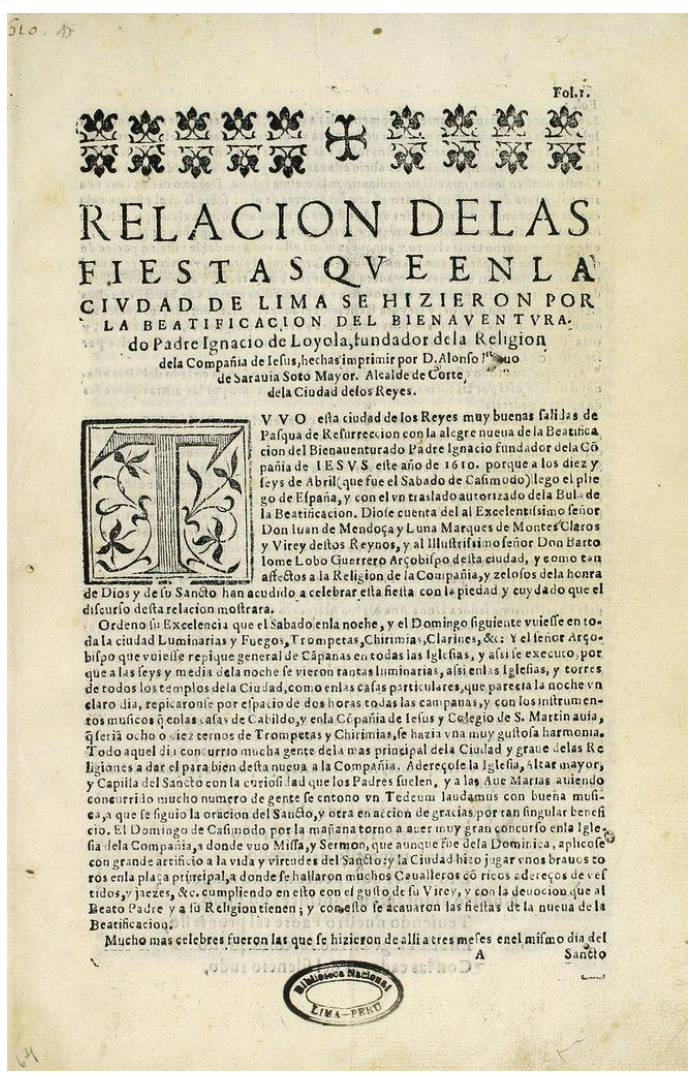

Fig. 17 Relación delas fiestas que en la civdad de Lima se hizieron por la beatificacion del bienaventvrado Padre Ignacio de Loyola, fundador dela Religion de la Compañia de Iesus... Lima, Antonio Ricardo, 1610.

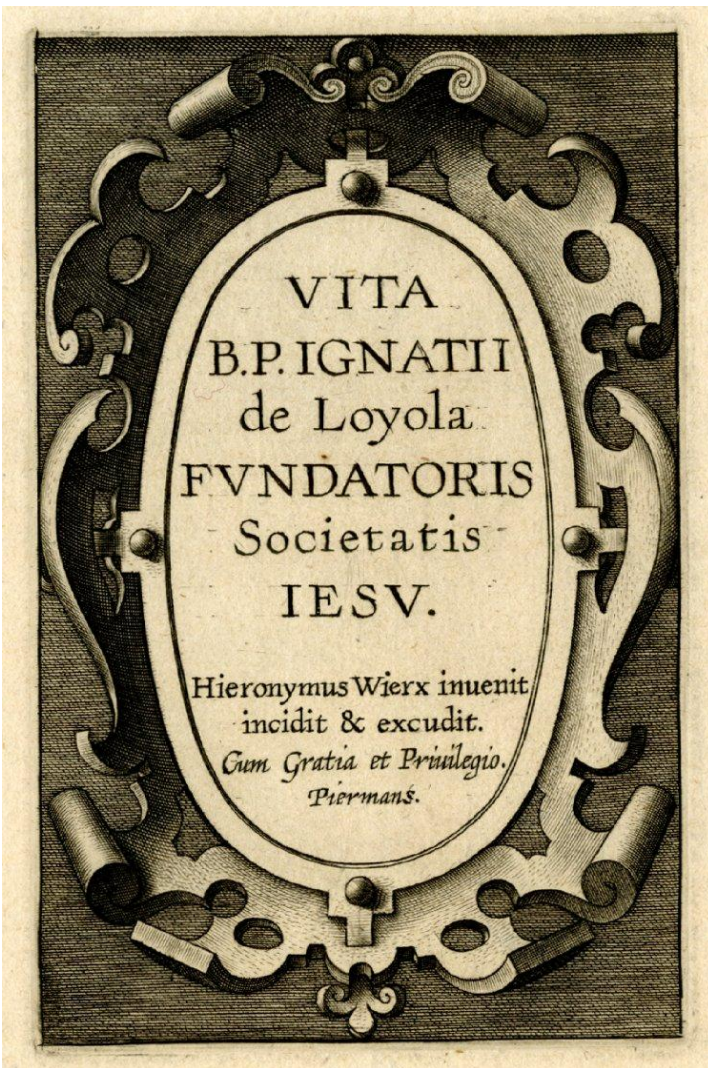

Fig. 18 Jerónimo Wierix. Vida de San Ignacio (c.1590-1609).

Otros ciclos se fueron continuando, como las 14 láminas compuestas en Flandes por el no menos conocido Hieronymus Wierix (Fig. 18). Fueron realizados hacia 1590 y publicados alrededor de 1613. Varios años después, el mismo Wierix, grabó los retratos de los generales.

Una vez canonizado, ya los artistas no se preocuparon por hacer conocer al Santo sino de exaltar y glorificar su figura (Fig. 19), como el "Triunfo de San Ignacio", del francés Claude Vignon, con clara influencia de Caravaggio, siendo una pintura barroca, con una iconografía muy reproducida. Y otra vez el gran Rubens, representando ahora la conocida obra "Los Milagros de San Ignacio" (Fig. 20), aún antes de ser canonizado. Un Rubens maduro que luego de 20 años se encargó de decorar, con 39 lienzos, la iglesia de los jesuitas en Amberes.

No solo en pinturas aisladas sino también en ciclos, incluso pintados por jesuitas como el P. Ignacio Raeth, quien compuso una serie de 36 cuadros en 1662. También se destaca el ciclo de 14 lienzos pintado por Juan Valdés Leal de 1665 para la Casa Profesa de Sevilla (3 perdidos y 11 en el Museo de la ciudad). Muchos otros grupos de pinturas, 
a los que se sumarán los americanos, como el ciclo de 22 cuadros que se conservan íntegramente del artista Cristóbal de Villalpando para el noviciado de San Francisco Javier de Tepozotlán. O, finalmente (Fig. 21) el ciclo de la iglesia de San Pedro en Lima, serie de 8 óleos que se atribuyeron en principio a Bernardo Bitti y luego se identificaron como del taller de Valdés Leal o al mismo sevillano. Una representación detallada en cuanto a personajes y escenografía. Pero esta serie ya pertenece a una renovada iconografía... con ángeles, santos, mártires y programas universales...

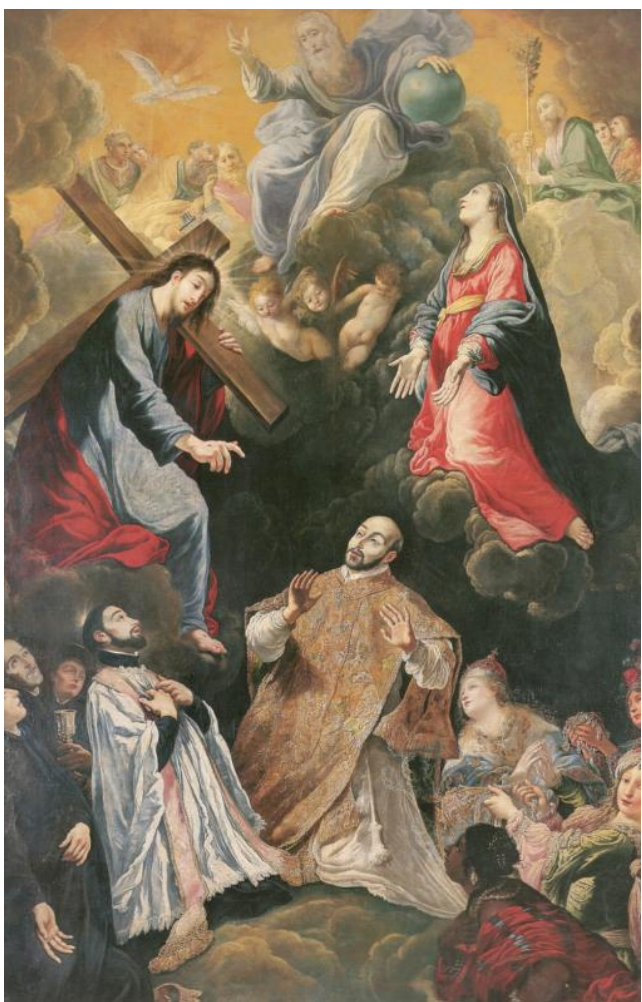

Fig. 19 Triunfo de San Ignacio. Claude Vignon Museo Bellas Artes Orleans.

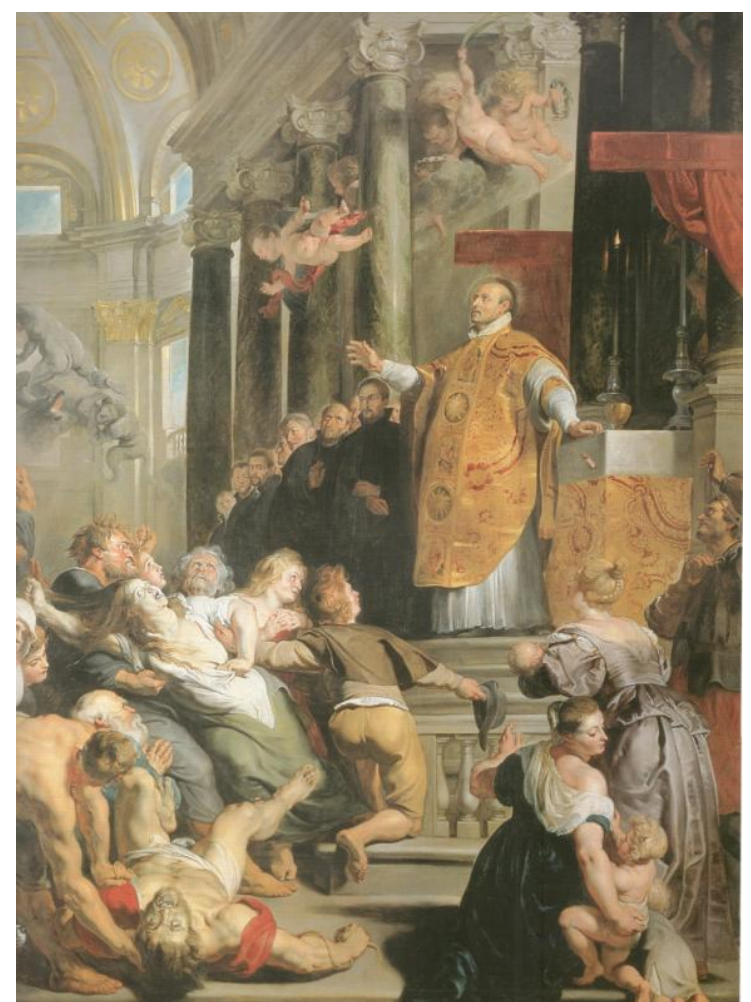

Fig. 20 Los milagros de Ignacio. Rubens Kunsthistorisches Museum Viena.

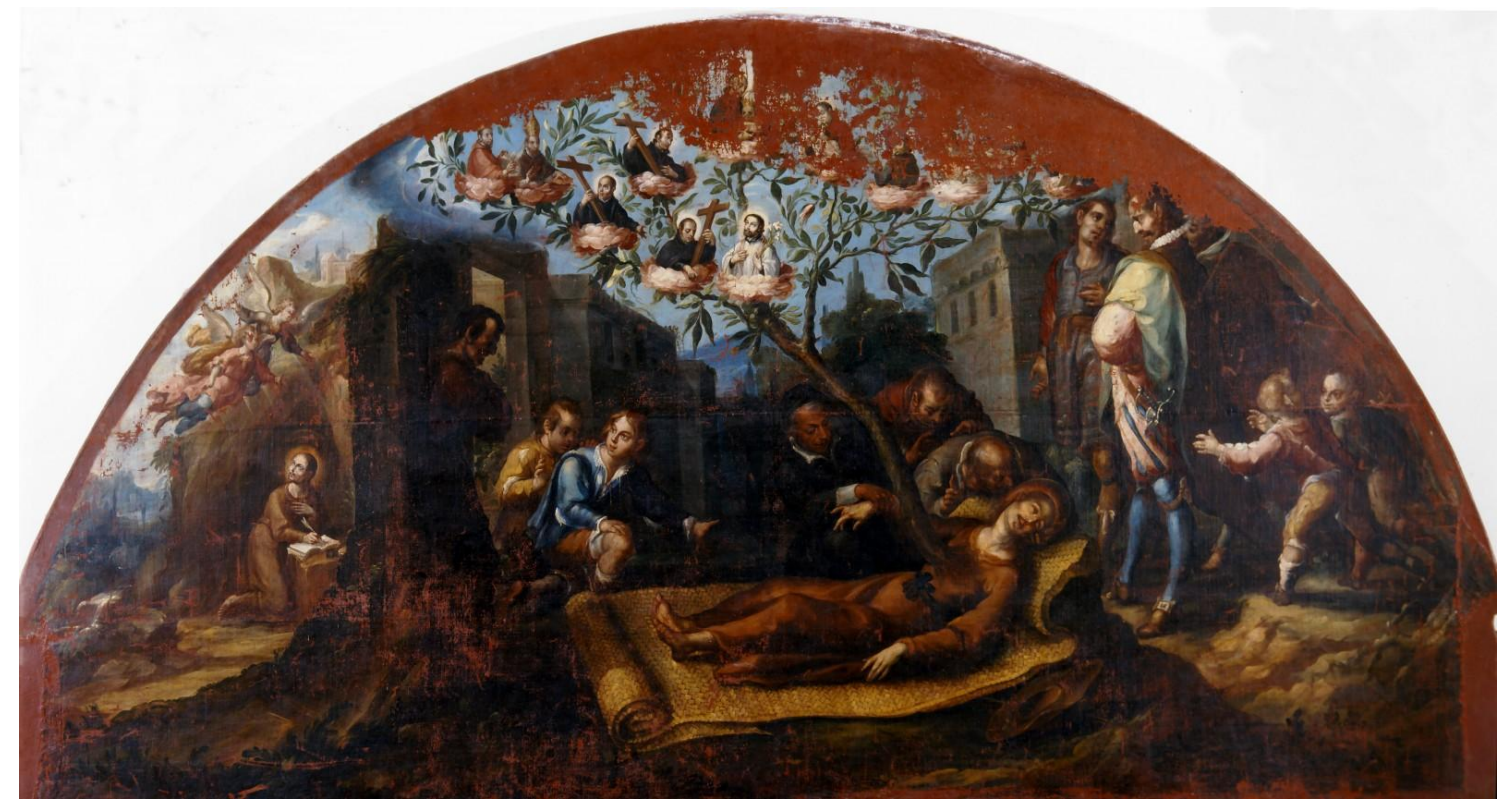

Fig. 21. Cristóbal de Villalpando Éxtasis de San Ignacio o El rapto en Manresa (INAH-Museo Nacional del Virreinato).

73 Carlos A. Page. Los primeros retratos de Ignacio y los inicios de la iconografía ... 63-75. 


\section{Reseñas bibliográficas}

Alison C. F. (2012). The "roles" of illustrations of the Lives of St. Ignatius of Loyola. En: Ardissino, E. e Selmi, E. Visibile Teologia: Il Libro Sacro Figurato in Italia tra Cinque e Seicento. Roma: Edizioni di Storia e Letteratura, pp. 115-125.

Arellano, F. (2004). Iconografía ignaciana en Hispanoamérica. Cuadernos Ignacianos, 5. Caracas: Universidad Católica Andrés Bello, pp. 79-93.

Autobiografía de San Ignacio de Loyola (Texto recogido por el P. Luis Gonçalves da Camara entre 1553 y 1555. El aleph http://ieee.unsl.edu.ar/librosgratis/gratis/Loyola.pdf

Barbé, J. B. (1622).Vita beati P. Ignatii Loiolae Societatis Iesu Fundatorris. Roma.

Cendoya Echániz, I. y Montero Estebas, P. M. (1993). La influencia de la "Vita beati patris ignatii..." grabada por Barbé en los ciclos iconográficos de San Ignacio. Cuadernos de arte e iconografía. VI(11), pp. 386-395.

García Gutiérrez SJ, F. (2006). Serie de pinturas de la vida de San Ignacio en Lima (Perú), Temas de Estética y Arte, XX, pp. 85-103.

Gutiérrez SJ, F. (2004). Los grabados flamencos de los siglos XVI y XVII y la Compañía de Jesús. Cuadernos Ignacianos, 5. Caracas: Universidad Católica Andrés Bello, pp. 31-37.

Iturriaga Elorza SJ, J. (1995). Vida de San Ignacio de Loyola en grabados del siglo VII, Bilbao: Mensajero

Leturia, P. de (1957). La mascarilla de San Ignacio. Estudios Ignacianos. Roma: Institutum Historicum.

Mauquoy-Hendrickx, H. (1978). Les Estampes Des Wierix. Bibliothèque royale de Belgique.

Maza, F de la (1963). Pintura barroca mexicana (Cristóbal de Villalpando). Archivo Español de Arte, XXXVI, pp. 21-38.

Maza, F de la (1964). El pintor Cristóbal de Villalpando. México: I.N.A.H.

Navas Gutiérrez. A. M. (1992). Vida de San Ignacio de Loyola en imágenes. Granada: Universidad.

Pfeiffer SJ, H. (2003). La Iconografía. En: Sale SI, G. (ed.). Ignacio y el arte de los jesuitas. Bilbao: Ediciones Mensajero, pp. 169-222.

Piriz Pérez, E. (2004). Una aproximación a la iconografía de San Ignacio de Loyola. Cuadernos Ignacianos, 5. Caracas: Universidad Católica Andrés Bello, pp. 19-29.

Relación delas fiestas que en la civdad de Lima se hizieron por la beatificacion del bienaventvrado Padre Ignacio de Loyola, fundador dela Religion de la Compañia de Iesus... (1610). Lima, Antonio Ricardo,.

Ribadenera SJ, P. (1587). Vita del P. Ignatio Loiola fondadore della Religione della Compagnia de Giesv. Venetia: Apressoi Gioliti. 
Rodríguez Gutiérrez de Ceballos SJ, A. (1969). Sobre los cuadros de la vida de San Ignacio de Loyola, pintados por Valdés Leal, del Museo de Bellas Artes de Sevilla. Archivo Español de Arte, 165, pp. 62-63.

(1971). Aportaciones a la iconografía de San Ignacio de Loyola. Goya, 102, pp. 388-92.

(1992). La iconografía de San Ignacio de Loyola y los ciclos pintados de su vida en España e Hispanoamérica. En: Plazaola (ed.) Ignacio de Loyola y su tiempo. Congreso Internacional de Historia. Bilbao, pp. 107-127.

(1994). El ciclo de la vida de San Ignacio de Loyola pintado por Cristóbal de Villalpando en Tepozotlán. Precisiones iconográficas. Ars Longa, 5, pp. 53-60.

Rubens, P. P. (1609). Vita Beati P. Ignatti Fundatoris Societatis Iesu Vita Beati P. Ignatii Loiolae Societatis Iesu Fundatoris. Roma.

Wierx, H. (c.1590-1609). Vita B. P. Ignatii de Loyola Fvndatoris Societatis Iesv. Antuérpia. 